\title{
Exporting the Silicon Valley to China
}

\author{
Gianluigi Negro ${ }^{1 *}$ \\ (iD) 0000-0003-2485-6797 \\ Jing $\mathbf{W u}{ }^{2}$ \\ (iD) 0000-0002-3177-1815 \\ ${ }^{1}$ University of Siena, ITALY \\ 2 Peking University, CHINA \\ *Corresponding author: gianluigi.negro@unisi.it
}

Citation: Negro, G., \& Wu, J. (2020). Exporting the Silicon Valley to China. Online Journal of Communication and Media Technologies, 10(3), e202016. https://doi.org/10.29333/ojcmt/7996

\section{ARTICLE INFO}

Received: 7 Feb 2020

Accepted: 9 Apr 2020

\section{ABSTRACT}

This article focuses on the history of Zhongguancun as one of the most important area used by the official Chinese narrative to promote the historical shift from the "made in China" model to the "created in China" one. We reconfigure this process through three historical phases that reflect the engagement of policymakers, business and high-tech agents in the creation of a specific social imaginary. Based on a textual analysis as well as on political and sectorial sources, this historical study argues that Zhongguancun carries a set of cultural values influenced by the Silicon Valley experience, however it still fails to achieve success in terms of creation and innovation. In detail, our article highlights three findings: Zhongguacun satisfied the conditions of creative area only during its first stage, when local industries had to adapt its services and products to the Chinese language and culture. Second, Zhongguancun shared with the Silicon Valley neoliberalists issues such as those related to the risk of a real estate bubble burst. Third, although Chinese documents show that Zhongguancun has not the same creativity outputs compared to the Silcon Valley, it shares with California its financial dynamics mainly driven by huge investments in innovation places like innovation cafes.

Keywords: Zhongguancun, Silicon Valley, Chinese ITC history, media history

\section{INTRODUCTION}

This interdisciplinary research starts from the necessity of combining two research areas that, at the present stage, looks distant. Namely, on the one hand, excluding remarkable exceptions, there is a limited number of studies about digital media history focused on China (Repnikova, 2017; Yu, 2011); on the other hand, beside some limited cases, we noted a quite partial analysis from Chinese studies on digital media history (Yang, 2009; Yu, 2017; Zhao, 2009; Zhou, 2006). Our aim is to fill the gap taking as a starting point the case of Zhongguancun, which is, historically speaking, the first creativity and innovation park in China: the goal of the article is to analyze the creation of Zhongguancun's social imaginary taking into account both forms of continuity throughout the creation process as well turning points. This study is inspired by the historical analysis of the Silicon Valley: it is the very first creativity and innovation park in the world (Barbrook \& Camaron, 1996) that witnessed the establishment of the most lucrative hi tech and Internet companies worldwide.

\section{State of the Art}

Scholars have argued that the success of the Silicon Valley has led to the spread and promotion of a welldefined model of financing, managing, and organizing technology firms (Casper, 2007). Mostly important, some publications have shown that the social imaginary of the Silicon Valley was supported by the emergence of particular social group like hippies and "virtual class" that reinforced the development of hi-tech sector first and the economy Internet era later (on the historical turn see Balbi \& Maugadda, 2018). Some studies have

Copyright (c) $\mathbf{2 0 2 0}$ by authors; licensee OJCMT. This article is an open access article distributed under the terms and conditions of the Creative Commons Attribution License (http://creativecommons.org/licenses/by/4.0/). 
analyzed the emergent and recent literary history of the "Silicon Valley novel" (Even \& Street, 2018), others underlined the role played by the cultural hegemony of the Silicon Valley's products in defining the idea of time, optimizing productivity and minimizing time wasting (Wajcman, 2018). A consistent group of critical scholars criticized the social impacts (Benner, 2003), labor divisions (Fuchs, 2014) and economic accumulation driven by "the Silicon Valley myth" warning about ongoing attempts to clone the Californian model around the world (Duff, 2016). While technical studies are still questioning whether the Silicon Valley model could be replicated in other areas (Cook \& Joseph, 2001; Etzkowitz, 2011; Fung, Aminian \& Tung, 2018; Henton \& Held, 2013), empirical researches have already demonstrated that it has been already tested in East Asia (KlinglerVidra, 2016); other scholars have also investigated the possibility to replicate the Silicon Valley model also in Europe (Aydalot \& Keeble, 2018).

The impact of Silicon Valley on the social imaginary at the worldwide level has been already noted by Castells in his Technopoles of the World, the Making of $21^{\text {st }}$ century Industrial Complexes. China is not an exception. Indeed, Silicon Valley has been the main cultural reference for China in the development of the Haidian district. Our article proposes an additional perspective analyzing the creation of a social imaginary of Zhongguancun, taking into account the interplay of Chinese government, business and high-tech sectors in re- elaborating and re-interpreting the Silicon Valley vision within the Chinese context. Chinese creativity industry with reference to creative parks has been already studied both empirically (Lindtner \& Li, 2012) and theoretically (Björner, 2014; Keane, 2007; Molnar \& Koen, 2015; Zhou, 2007).

\section{Relevance}

The importance of ITC industries in China is justified by at least three reasons.

First, it is important to shed light on a series of policies (Francis, 1996) that started to be implemented in the 1970s in the computer industry first (Warner 1999) and in the Internet market later Arsène (2012), Negro (2017).

Second, in Zhonggguancun there have been successful business stories, at least at national level, such as Lenovo, Baidu and Sina but also JD and more recently Meituan Dianping. The history of Zhongguancun reflects the shift of Chinese economy from one that is investment driven to one that is consumption driven, which is now further promoted by Xi Jinping's policy. Two relevant examples of this shift can be traced in the two Zhongguancun based companies with the worldwide valuation such as Toutiao (Bytendence) and Didi Chuxing. The impact of these two companies is relevant not only in the emergent market fields such as artificial intelligence but also in more traditional ones like automated transportation. Furthermore, the success of Chinese companies in Zhongguancun like Baidu in the field of search engine, Sina in the online news sector and more recently, Toutiao (Bytendence) and Didi Chuxing fits with the emergent academic discussion on the role "corporational determinism" apathy proposed by Natale, Bory, and Balbi (2019). Indeed, these companies in Zhongguancun have had (or still have) the power of influence perceptions and behaviors of consumers, stakeholders and policymakers. Their political economy relevance is justified by the estimation according to which Internet-driven innovation can increase by up more than 20\% of China's GDP between 2013 and 2025 (Fung, Aminian, \& Tung, 2015).

Third, we argue that studying the history of Zhongguancun is important also at the international level especially for the hi-tech enterprises. As of March 2020 there were more than 400 unicorns around the world: among the six companies with the highest value, three were based in the Silicon Valley (SpaceX, Stripe and Airbnb) and three in Zhongguancun, namely: Toutiao (Bytedance) ranking the first position with a valuation of $\$ 75$ billion; Didi Chuxing ranking the second position with an evaluation of $\$ 56$ billion and Kuaishou at the sixth position with a valuation of $\$ 18$ billion. (CN Insights, 2020). 


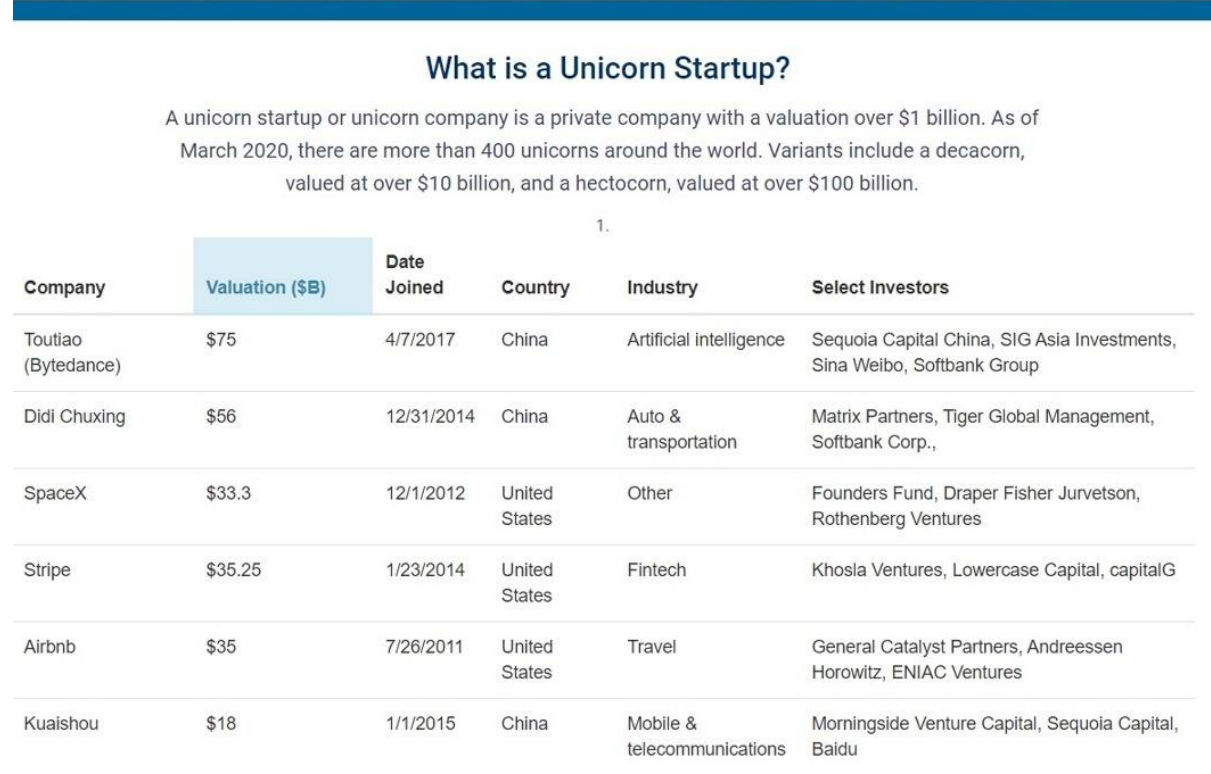

Figure 1. Top 6 Companies in the Global Unicorn Club, March 2020(CB Insighs, 2020)

This last trend reflects a shift in the geopolitics of information and shows the emergence of new trends in the of the global digital capitalism scenario mainly led by the U.S. from the end of the " 70 to the end of the 2010s (Schiller, 2011).

Beside the role of Zhongguancun, this paper contributes to further develop the discussion on the evolution of China's information technology and the creation of its social imaginary that, according to some scholars, are largely ignored in the post-revolutionary reform discourse (Wu \& Yun, 2018, p. 8). New discourses on how information technology can change China are the result of a reform ideology that defines a turning point between pre and post reform society in China that "looks mostly for guidance in areas of economic and technological modernization" (ibid.). In this respect, the experience of Zhongguancun provides a useful example.

From a methodological perspective, this article pays attention to the ways in which cultural values, political ideologies and social imaginations impact and influence the development of information industry. In detail, this study is in line which the work of Fred Turner: in his From Counterculture to Cyberculture: Steward Brand, The Whole Earth Network and Rise of Digital Utopianism (2006) he shows that the way in which a particular society imagines the future represented by technology it affects the development of the society itself like in the case of Silicon Valley: it was initially celebrated as the most important place in North America to support the counterculture but eventually it became a clear expression of neoliberalism and market consumption, embodying the exact opposite values of antiestablishment, justice for subaltern groups and individual freedom that where initially advocated when the first idea of Silicon Valley was shaped.

Following Peet suggestion to "employ cultural terms such as symbol, imaginary and rationality" (Peet, 2000) we argue that the analysis of the imaginary plays a historical crucial role in supporting the understanding of the so called Zhongguancun model.

At the theoretical level, the experience of Zhongguancun echoing Etzkowitz research is useful to understand two characteristics of the Silicon Valley model: on the one hand, it is unique because of its lack in unifying political structure, foundations and organizations which makes it an "organization-less" brand; on the other hand it's replicable because its implementation is based on the interplay of different actors, namely "Double Helix" (university - industry or government - university) as well as "Triple Helix" (university- industry - government) (Etzkowitz, 2019, Etzkowitz \& Zhou, 2017).

Practically, this article aims to answer to two research questions: 
- What have been the forms of continuities and breakpoints in the Chinese media and Chinese policy papers narrative(s) of Zhongguancun?

- What is the impact the Silicon Valley had played (and is it still playing) in the creativity industries in Zhongguancun and in shaping its social imaginary?

\section{SOURCES AND METHODOLOGIES}

This article investigates similarities and differences between the Silicon Valley model and Chinese social, political, economic and historical background contributing to further develop the existing literature (Trunina, Liu \& Chen, J. 2018). At the theoretical level, this research is focused on the imaginary studies taking into account world building within and across media not as dynamic entities of media themselves but as trans narrative, trans medial and trans authorial in nature and thus compelling objects of research for media studies (Wolf, 2014). Our study is influenced by Barbrook and Cameron (1996), as well Taylor (2004) researches, highlighting both the continuity and the "crucial juncture and loose alliance of writers, hackers, capitalists and artists [...] in defining a heterogeneous orthodoxy" (Barbrook and Cameron, 1996, p. 2) for particular ages. Our argument is that although following a different path, the pioneering work of the community media activists has been largely recuperated by the hi-tech and media industries in the Silicon Valley as well as in Zhongguancun. It is true that, compared to the case of the Silicon Valley, China did not experience the contribution of the hippy culture because of different cultural and historical reasons. However, in California, as in Beijing, it occurred a phenomenon already noted by Dyson: "market after market is being transformed by technological progress form a natural 'monopoly' to one in which competition is the rule" (1996). As empirically demonstrated by Mazzucato (2011) and Wolf (1968), without the "do it yourself" culture, the Silicon Valley myths would not have the global resonance as today quite similarly, without the cultural influence of the Chinese open market policies started by the end of the 1970s, Chinese entrepreneurs would have not played an important role in creating fundamental conditions for the development of Zhongguancun. A useful insight on this concern is provided by Chris Anderson prominent hi-tech journalist and head of TED talks organization who in his The Long Tail (Why the future is Selling Less of More) highlights "we can treat culture not as one big blanket, but as the superimposition of many interwoven threads which are individually addressable and connect different groups of people simultaneously" (2007). The shift suggested by Anderson supports an evolution of a cultural infrastructure as well as the networks of organizations, facilities and practices of arts and culture that have evolved in different urban regions (Borrup, 2011).

Lastly, yet important, we argue that the role played by the respective governments, national labor force or wider communities is often underestimated by US and Chinese capitalist entrepreneurs, whereas, the role of governments is supportive for a narrative of cybernetic libertarianism.

We argue that the history of Zhongguancun can be divided into three stages. The first one, which can be referred to as "the Chinese creative district prehistory", goes from the end of the 1980s to the end of the 1990s, when the constitutive choices were made (see Paul Star's 2004). At that time, the main focus was to catch up with Western technology, investing on manufacture and assemblage in the computer's fields in particular. The second stage goes from the end of the 1990s to the beginning of the 2000s and is characterized by the idea of cultural creativity (创意). During this period, the main policies were aimed at developing hi-tech products created and designed in China. China started to play a more relevant role in the global chain production in which the importance of copyright was crucial; in other terms, there was a shift from manufacture to creativity. The third stage starts at the beginning of the 2010 s and it ends in 2018. During this period, Zhongguancun experienced a shift towards innovation (创新) technology trying to catch up with other Asian countries (South Korea and Japan in particular), with a higher production of patents: during this third stage we witness a shift from creativity to innovation.

The analysis of these three periods is aimed not only at providing a historical analysis per se, but it is useful to contextualize the present situation of Zhongguancun, which is no longer the only creativity and innovation park in China.

We conducted a textual analysis referring on two main sources that are Computer World (计算机世界) and Zhongguancun (中关村). 
The first set of sources is a journalistic one, indeed the first magazine is one of the most authoritative IT Chinese magazines focused on technology; the second one is a monthly magazine with commentaries and analysis on Zhongguancun district launched in 2003. We selected these two sources because they both reflect a well-defined business mentality influenced by the American social imaginary. Computer World was launched in 1980 as the result of a joint venture between the Electronic Science and Technology Information Institute (under the supervision of the Ministry of Information Industry) and American Internal Data Group (IGD), a data and marketing service and venture capital corporation funded in Massachusetts, United States, in 1964 and acquired by the Chinese company China Oceanwide in March 2017. While Computer World covers the most important Chinese domestic and international hi tech business trends, Zhongguancun has a more domestic and specialist dimension focusing its reports and analysis on the Haidian district. All in all, the two magazines match the goals of this study because they cover the hegemonic discourse in the development of Zhongguancun reflecting the debate of policymakers, entrepreneurs, investors and hi-tech experts.

We retrieved the most significant articles through a search on China National Knowledge Infrastructure database $(\mathrm{CNKI})^{1}$ : Eventually we manually coded every single article selecting content with a consistent reference to the topics analyzed in the article and including references to policymakers, entrepreneurs and regulations and policy documents. We excluded from our analysis all the articles with generic references to our study. We focused our analysis on the narrative character of media content considering its potential as a site of ideological negotiation and its impact as mediated reality (Fursich, 2009) In the case of Computer World we retrieved 97 articles based on the keywork "Zhongguancun".

For the second set of sources we referred to political documents, four in particular:

- 1989 Notice of the Beijing Municipal People's Government on Adjusting the Regional Scope of Beijing New Technology Industry Development Pilot Area (北京市人民政府关于调整北京市新技术产业开发试验区区域范 围的通知);

- 1999 On the Implementation of Rejuvenating the Country through Science and Technology (关于实施科教兴 国战略加快建设中爸村科技园区的请示);

- 1999 Replies On the Construction of Zhongguancun Science Park (国务院䏍于建设中矣村科技园区有爸问题 的批复);

- 2009 Reply of the State Council on agreeing to support the construction of the National Independent Innovation Demonstration Zone in Zhongguancun Science Park (国务院䏍于同意支持中爸村科技园区建设国 家自主创新示范区的批复).

\section{DATA ANALYSIS, EMPIRICAL OUTPUTS, DISCUSSION}

From a quantitative perspective the results provided by CNKI database show that Computer World had published 97 articles focused on Zhongguancun, the highest coverage was from 2003 to 2005 with 20 (2003), 22 (2004) and 13 (2005) articles published respectively.

\footnotetext{
${ }^{1}$ With one of the keyworks in the title on in the description
} 


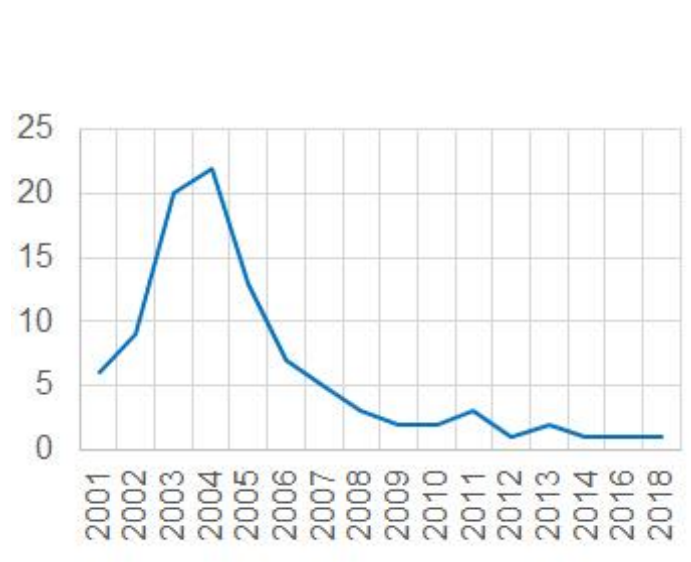

(a)

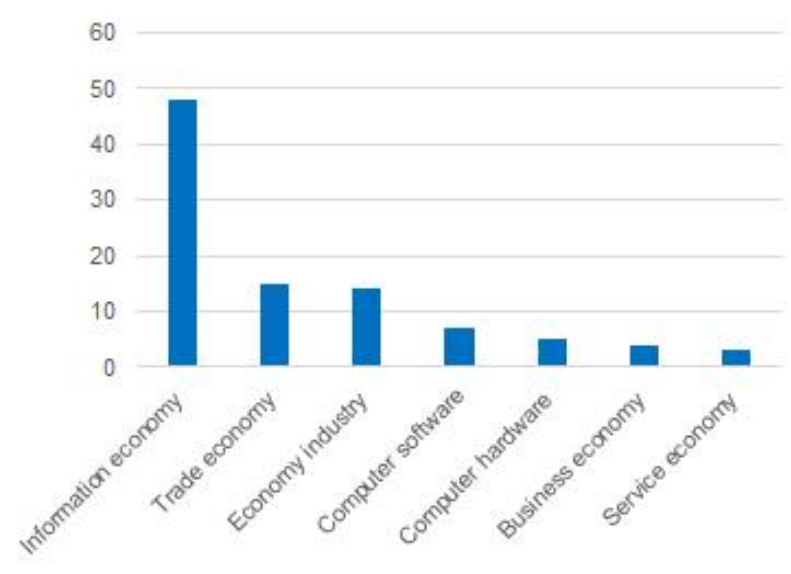

(b)

Figure 2. a) Number of articles published on Computer World magazine focused on Zhonggauncun b) Catetories of articles published on Computer World magazine focused on Zhonggauncun

Basically, all the articles focused their attention on the information economy. A relevant emphasis had been placed also on trade and economy (15 articles) and industrial economy (14 articles).

We retrieved more results from the Zhongguancun magazines. The highest rate of articles published by the magazine was in 2013 with 650 articles published, the year with the most limited articles published on the topic was 2006 with 450 articles published. Overall, from the first issue in 2003 to December 2018 we counted 95 articles with Zhongguancun in their headlines. Eventually, we made other searches with other three keywords useful for this research that are "Creativity", "Innovation" and "Silicon Valley."

Based on a timeframe from 2003 to 2018, we collected 1450 articles with titles or headlines focused on "creativity", 160 articles focused on "innovation", 530 on "Silicon Valley". Content wise, our hypothesis (more emphasis addressed to the concept of innovation instead of creativity) finds a confirmation at least on a historical dimension. Indeed, we noted that the highest publication of articles focused on creativity is 2005 2006 with 21 and 23 articles published respectively. Whereas, in the case of innovation, the peak of publication is more recent: it starts in 2014 with 127 articles and it ends in 2018 with 132 articles. This shift of wording is consistent not only with our hypothesis but also with the more general economic Chinese shift (Ding \& Li, 2015).

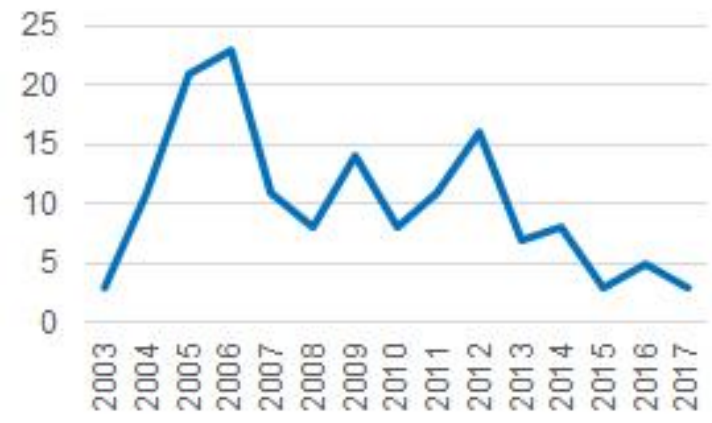

(a)

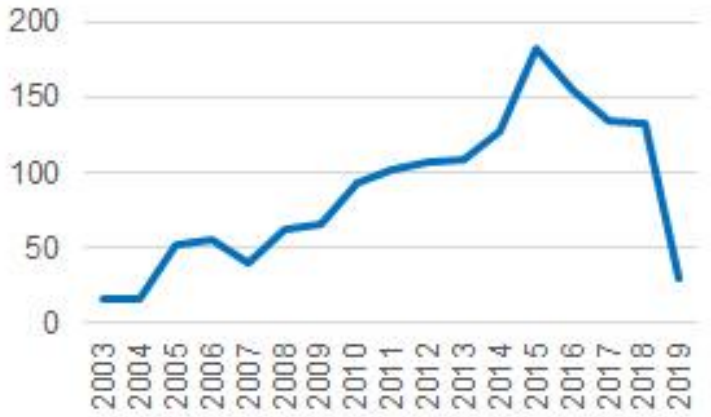

(b)

Figure 3. Number of articles published on Zhongguancun magazine focused on (a) creativity and (b) innovation

Our empirical analysis for this stage is limited because according to the results provided by our search on the CNKI database, both Computer World and Zhongguancun magazines had no articles published before 2001. Hence, we referred to two policy documents that focus on Haidian area. This section intends to provide a set of three main similarities between Zhongguancun and the Silicon Valley.

The first one is geographical. Both the California region and the Haidian district were established near a university campus. But, as it will be also confirmed by our sources, if Stanford established a virtuous system 
of knowledge transfer between its campus and its close private environment, Beijing Tsinghua University, Peking University and China Academy of Sciences were not successfully linked to the private sector.

The second similarity is based on political economy. Indeed, on the one hand, both the Silicon Valley and the Haidian district embrace (or, in the case of Zhongguancun, has the ambition to embrace) neo liberalist values; on the other hand, they were fully supported by national governmental policies and strategies that contributed to create infrastructures and to set the rules for companies (and economies) to grow: in this process, beside creating the 'conditions' for innovation, the government intervention proactively promoted a development strategy around a new high-growth area, before the potential for investment was understood by the business community. Lastly, the two models increased the freedom of venture capitalists to invest in military, state and university projects (see Mazzuccato, 2011).

The third and last similarity is both economic and geographical. Indeed, if is Silicon Valley there is a direct connection with the imaginary of the San Francisco Bay (旧金山湾区), the Beijing Haidian district can be considered a special economic zone with a focus on hi tech and innovation development, likewise Guangdong cities in the 70s were considered Special Economic Zones. The Californian and Beijing areas share similar geographical and economic dynamics in terms of rationale (hi tech and innovation), local incentives (taxes and special financial supports), market agents (real estate industry and labor force migration). More than the others, this third similarity fully reflects the role of the imaginary in the creation of "new world spaces" that are both globalized and very local combining the movement of capital, images and technologies. In other words, it sees the clash (or the coexistence) of global and local imagined districts (see Chow, Harootunian, \& Miyoshi, 1996).

\section{From 1988 to 1999: A Top Down Political Plan}

Coming to the case of Zhongguancun, form a Chinese planning perspective, the very first policy document was issued by the Beijing Municipal People's Government and approved by the State Council on May 10, 1988. Basically, Zhonggauncun area was selected to be established as "an export-oriented and new technology industry development test area" (State Council, 1988). A series of tax reduction was proposed for the most performing technology enterprises both domestically and internationally. In general terms, this period fully reflects the trend of Chinese reform efforts. Indeed, not only a series of taxes or value added taxes import and export duties on technology products were exempted after the approval of the new relevant state regulations, but the scientific and technological personnel in scientific research units, schools and enterprises was encouraged, along with the incentive for new technology companies, to recruit college graduates, university students both domestically and internationally, as well as foreign experts (ibid).

Eleven years later the Ministry of Science and Technology of Beijing Municipal People's Government issued the "Reply of the State Council on the Relevant Issues Concerning the Construction of Zhongguancun Science and Technology Park" and the "Request for the implementation of the Strategy of National Rejuvenation for Science and Education to Accelerate the Zhongguancun Science Park" on June $16^{\text {th }} 1999$ (State Council, 1999).

After more than a decade, the Haidian area was selected to become a "Science Park to implement the rejuvenation of the country and to enhance China's innovation capability and the overall national strength". The area was not only aimed at accelerating the economic and social development of the capital, but it was also supposed to play as a model for the development of the capital and of the national high-tech industry. One of the most important goals of Zhongguancun was to reform the market economy that, by the end of the 1990s, was lagging behind. According to the policy document, the combination between science and technology was not close enough. Universities could not train engineers and personnel competitive for the market. This negative trend affected the area with a lack of attractiveness for outstanding talents, insufficient motivation for technological innovation and venture capital supporting the development of high-tech industries.

The main goals were to increase the international competitiveness based on the capital and national wide scientific and technological achievements through the creation of incubators to attract and also to train talents. The target was to make Zhongguancun a "world class city" in 10 years.

It is possible to argue that Zhonggauncun can be considered a watershed for the Chinese history of scientific research. Indeed, Beijing Haidian district represented a shift form the national defense led scientific 
research to a more civilian oriented one. In detail, the policies implemented by Deng Xiaoping made were orientated to transform Zhongguancun in the pilot area to support the development of technology in China serving the national economy (Zhou, 2008). It is worth mentioning that this shift was possible also for the contribution of a group of scientists, formerly involved in military projects. These scientists, after Mao's death, urged the government to invest on civilian research projects submitting a new program that was supported by Deng himself. This project was named "program 863" referring to the time Deng endorsed the initiative in March 1986. When the 863 program was launched it had very ambitious goals aimed at narrowing the technology gap with Western countries, USA in particular, supporting huge investments in fields such as new materials, information technology, biology, energy and automation among the others (Feigenbaum, 2003). Although the project had no concrete results, its main success was to train a generation of experts who eventually contributed to develop the technology value of Zhongguancun. That said, there were still serious issues to be addressed, such as the lack of connectivity between academic institutions and the market and the lack of collaboration between research centers in Beijing. Another serious problem was the sustainability of 863 program: because of the economic problems caused by the policies under Mao's era, the majority of public institutions were unable to provide their employees with basic necessities such as housing. Thus, public institutions were consistently under financial pressure. Mao's legacy had its effects not only at the economic level but also at the cultural level. As Zhao reports, during the 80s many intellectuals were frustrated, as demonstrated by the popular saying circulating in China at that time: "those designing the missile (导弹) have lower earnings than those selling chicken eggs (鸡蛋); those fixing the inside of the brain (brain surgeons) have lower earnings than those fixing the outside of the brain (barbers)" (2008, p. 35). Nevertheless, coming back to the contribution of the 863 program, it should also be noted that the reintroduction of the university entrance exams and a more general positive perception about science and higher education with Deng, made it possible to transform some nerds into national celebrities. This was the case of Chen Jingrun, a mathematician from the Chinese Academy of Sciences who started the first privately run science and technology entity in Zhongguancun, the "Department of Technical Services and Development of the Beijing Society of Plasma". Even more popular is the experience of Chen Chunxian, a research professor at the Chinese Academy of Sciences at the Beijing Institute of Physics who, after his visit to the Silicon Valley, in the late 1970s decided to open a company himself called "Advanced Technology Service Association" in Zhongguancun in 1980. Although his company did not record any economic success, it inspired other colleagues at the Chinese Academy of Sciences, Peking University and Tsinghua University who benefited also from the more liberal market conditions. One useful example in this sense is provided by the establishment of Lenovo. The today famous Chinese computer corporation is the result of the creation of a Zeng Maocao, a professor of the Institute of Computation at the Chinese Academy of Science who launched a startup company with a government grant of 200,000 RMB. In 1986 Prof Zeng was informed that no more economic allowances would have been addressed to the company. As result, Prof Zeng sent a desperate letter to the Chinese Academy of Science refusing the suggestions provided by the government to dismiss the majority of the staff of 1500 employees and probably in a desperate reaction of pride and frustration, promised that he would have changed the activity of the company moving to "fixing bicycles" (Ling, 2005). Although provocative, this anecdote is quite useful to provide a general idea of Lenovo during its first years engaged in trading different tech devices from electric watches to color TV. Furthermore, the interest in pure research was demonstrated by new policies of public institutes that supported departing researchers and scientists keeping their positions at the institutes and providing them employees with housing while cutting off managers salaries (Ling, 2005; Zhao, 2008). In this new scenario, the role of public institutes was to reduce market risk of departing scientists using the job security benefits provided by the state.

This necessity of market development brought to a situation according to which there was an over production of state-owned enterprises focused on assembling PC clones using components imported from Hong Kong. According to Wood, in 1992 PC was still part of a small part of the Chinese pictures. PC were still too expensive for the population. Indeed, a PC average cost was about 30 times the average annual salary of an urban city worker" (1992, Zhao, 2008). That said, Chinese market conditions on the one hand and the negligence of big computer corporations on the other, created the conditions for Chinese PC producers to occupy niche market that eventually became bigger thanks to ad hoc high- tech products such as digital printing system, Chinese PC typesetting and Chinese language computer card that could search Chinese 
words automatically. This set of services was created by the engineer Ni Guangnan and named Liangxiang (联想) (eventually rebranded as Lenovo).

The academic role of the Institute of Computation at the Chinese Academy of Sciences was not related to its role of research and development, instead its main contribution to Lenovo was pivotal. Being implicitly supported by the government was essential to obtain loans from the banks. Furthermore, Lenovo stateowned status was fundamental to establish a joint venture in Hong Kong, a possibility that at that time could not be implemented by a private company (Zhao, 2007). By the end of the 1990s, Chinese market had not been developed yet. Even more in the 1980s, China was still characterized by a planned economy: this was particularity visible in Beijing, more than in other Chinese areas in the south that benefited from the status of special economic zones. Lastly, Lenovo and other PC assemblers (mainly 民营, people run enterprises) played a fundamental role in providing the first computers to research institutes and offices especially in Haidian district. The mushrooming of 民营 enterprises with a focus on PC manufacturing and assembling, combined with a growing market demand, led to establish a parallelism of Zhongguancun during this stage with the first years of Californian Silicon Valley, a comparison that was later on recovered by the same Chinese press that labeled Zhonggguancun the "Chinese Silicon Valley". However, this comparison, at least during this stage, is inappropriate. While, during its first years, the Californian dynamism was mainly supported by R\&D inside the companies, Zhogguauncun's vibrancy was the result of a series of research establishments that decided to obtain profits from the market. The main difference at this stage was that while in the USA the commercial attitude was supported by a strong liberal cultural environment, in Zhongguancun the majority strong forms of cooperation were limited to research institutes that had no experience with financial procedures and business management. A gap that, as our sources show, would have taken time to be reduced. These issues became even more complex to solve during the last years of the 90s. It was in these years that most major American and Japanese electronics companies launched their activities in Zhongguancun ${ }^{2}$ (Wang \& Wang, 1998). Foreign corporations' cooperation with 民营 companies has both a positive and negative view. On the one hand, 民营 companies became the main intermediaries to introduce foreign market products into China reducing the Chinese technology gap with Western countries as well as supporting a consistent expansion in terms of technology products' volume; on the other hand, the priority placed on the market negatively affected investments and the general interest in carrying out research and development as required by national policies. The firms that in the 1980s were able to develop ad hoc services and applications for the Chinese market were replaced by international products. The most emblematic case was the success of Microsoft Windows operating system also available in the pirate market that marginalized the presence of Chinese language software (Zhao, 2008).

Overall, the influence of foreign corporations had a negative impact on the 民营 in terms of technological innovation, market share and human resources. Indeed, the opening market reforms had an influence also on the job market. In the 1990s the wages of Chinese intellectuals increased a lot also because of the presence of international corporations whom salaries were ten times higher than the ones provided by local firms. Furthermore, the most talented students were affected by an "MBA fever": indeed, by the end of 1999, there were 23,500 students taking MBA courses in line with government request to find high quality business leaders (Gittings, 2005). This cultural milieu contributed to boost the imaginary of Western countries as the best ones to obtain a higher education, the influence of the American business culture in particular, played a relevant impact on the nascent Chinese urban middle class. The most popular books among Chinese students at that time were Harvard Girl (2000), a novel on the story of ambitious parents -authors of the book - who supported their daughter Liu Yiting to get a Harvard scholarship and other imitations such as Harvard Boy and Cambridge Girl (Rosen, 2004; Meng, 2018). Against this political, social and economic backdrop, conditions to peruse a model apparently without Chinese characteristics and closer to liberal values emerged.

\section{From 1999 to 2009: This is not Silicon Valley, Creativity Needed}

During the second decade of its history, the policies of Zhongguancun were oriented to increase the creativity of Beijing Haidian district not only with the aim for it to become a model for the whole country in

\footnotetext{
${ }^{2}$ Among them IBM, Compaq, Intel, HP, Epson, Microsoft, General Electrics, Canon, Hitachi, NEC, Mitsubishi.
} 
terms of economic development but also to reach the status of top city in the field of creativity in Asia. In order to reach this goal, the State Council renamed the area in Zhonggauncun Science \& Technology Zone including other six parks to Haidian Park (namely, Fengtai Park, Changping Park, Electronics City -in Chaoyang)-, Yizhuang Park, Desheng Park, and Jianxiang Park). Beside investing in promoting Zhongguancun's profile, the central government provided financial support to the Zhonggguancun. Indeed, in December 2000, after the $11^{\text {th }}$ People's Congress of Beijing Municipality, new regulations of Zhongguancun Science and Technology Park were adopted. These new regulations encouraged enterprises, universities and research institutions to set up joint ventures or institutions engaged in technology innovation. The regulations also established fiscal support from the government and forms of cooperation between universities, research institutions and enterprises (art 13). The technical support was also encouraged by the government through fiscal funds allocation and equity investments (art 28).

Our selected sources show that during this second stage, this government plan failed because of several reasons. In general, most of the editorials analyzed for our study suggest that Zhongguancun had still to take inspiration from the Silicon Valley model, in terms of financial structure and ecosystem, in order to support a coherent development.

Indeed, Zhongguancun's tendency to take inspiration from the Silicon Valley was already clear in November 2000 when an article on Computer World magazine, titled "The story of the capital in Zhongguancun", highlighted the capital investment as one of the main differences between the Haidian district and the Silicon Valley. In detail, the article highlighted "how USA small and mid-size companies are constantly selling sharings of their companies to banks getting back financial support [...]. whereas, in China no investment bank is willing to issue lones for a company without reputation because this is prohibited by the domestic security law". (Computer World, 2000). The most direct critic in the article is visible in the following excerpt: "to have no market is even better than to build an immature market". The article also highlighted the concerns of Premier Zhu Rongji who expressed the need to attract experienced bankers and financial experts from Hong Kong and Singapore to help domestic capital markets. Also, in this case, differences were not only technical but also cultural.

In February 2003, for instance, former web entrepreneur Fang Xingdong lamented the lack of a proper innovation index applied to Zhongguancun area to monitor its innovation development. He contested the fact the Zhongguancun was stuck to use "indicators sued for traditional industries that do not truly reflect the innovation ability and vitality of high- tech regions". Whereas, the indicators of the Silicon Valley privilege "the number of gazelle companies ${ }^{3}$, the amount of venture capital and the number of listed companies on NASDAQ". Fang Xingdong invited to refer to a more update "scientific and effective indicator system as soon as possible [because] Zhongguancun has today a great economic strength (Computer World, 2003). Concerns on the Haidian district were expressed even more clearly on another editorial published on Computer Word in August of the same year and in which three main issues were presented: "First, the fact that Zhongguancun should not become a distribution center for world electronic products. Second, the necessity to carry out specific policies for the construction of a model for Zhongguancun similar to those in the Silicon Valley. Third, the importance of taking inspiration form the Silicon Valley in developing a market which is service oriented reconfiguring Zhongguancun status quo mainly based on the production and assemblage of products" (Computer World, 2003). A further inspiration from Silicon Valley for Zhongguancun is represented by the importance addressed to applied research. An article published on June 2004 on the magazine Zhongguancun implicitly criticized the role of Peking University, Tsinghua University and the Chinese Academy of Sciences suggesting the "Zhongguancun should establish an ad hoc university to consolidate and create a new culture through the university". Another article on the same magazine published again on June 2004 titled "Silicon Valley is not accidental" did not only emphasized the strategic importance of research and innovation

\footnotetext{
${ }^{3}$ According the definition of Investopedia "a gazelle company is a high-growth company that has been increasing its revenues by at least $20 \%$ annually for four years or more, starting from a revenue base of at least $\$ 100,000$. This growth pace means that the company has effectively more than doubled its revenues over a four-year period. As gazelle companies are characterized by their rapid sales growth pace, rather than their absolute size, they can range in size from small companies to very large enterprises, though a majority of them are on the smaller end of the scale.
} 
supported by the US National Science Foundation but it also focused on the role played by industrial enterprises to support research funding.

Every year, the United States invests huge amounts of research funding, more than 100 billion US dollars, more than the total investment of Japan, Germany, France and the United Kingdom combined together. The proportion of US research funding to the gross national product is currently about $8 \%$. In the past 10 years, the growth rate of US research funding has been about 5\%, exceeding the growth of the gross national product. The vast majority of research funding in the United States comes from the federal government and workers enterprise. In particular, basic research funding is provided primarily by the federal government in the United States. For higher education institutions, more than half of their research funding is provided by the federal government. Higher education institutions undertake more than half of the nation's basic research tasks; the National Science Foundation mainly supports university research. Industrial enterprises are not only the main body of development and application research, but also the main force of basic research, and their status is second only to higher education institutions.

Another relevant gap between Silicon Valley and Zhongguancun is the entrepreneurial mentality. An article published on Zhogguancun on August 2004 pointed out that there was still a confusion about the differences between the role to be played by managers more inclined to "manage an existing business and not willing to take too much risk" and entrepreneurs who bring "new ideas and markets from the scratch [...] and inclined to take risks" (Zhongguancun, 2004).

Lastly, an editorial on the magazine Zhongguancun published already in November 2002 lamented the interference of the real estate market: according to the report, already at that time "medium and large sized companies have a serious lack of office space with 2.2 million square meters of office space available". Even more critical was the comment of the editorial according to which:

the innovation spirit of Zhongguancun had been compromised by the fact that enterprises tried to get office spaces through unscrupulous land policies and government fiscal support and this phenomenon evolved into a 'real estate movement'. [...] When more than $50 \%$ of working capital is consumed by rent, the survival of the company becomes a source of anxiety, and therefore development and growth are relatively difficult to achieve. The simplest reason why many companies have left Zhogguancun is that they cannot afford the rent of 'IT landlords.'

The rent issue is something that Silicon Valley also experienced in the past. As Barbrook and Cameron argue in their "The Californian Ideology", the high tech Californian district was supported by a parallel history of both venture backed capitalism and radical anti-establishmentarianism: this cultural milieu supported the creation of a narrative that encouraged three key elements: the social development through the increase of computer technologies (1996), the success of entrepreneurial technology culture based on the success of smartest and hardest workers and more importantly, the idea that universal property is best pursued through an unfettered free market (see Marwick 2013). In general, the shift towards Californian ideology has its roots in the unquestioning acceptance of the liberal conception of the individual which finds its ground on the idea of protecting the freedoms and property of individuals against oppressive laws (Barbrook and Camerdon, 1996). While the Silicon Valley ideology has its historical roots in the American Declaration of Independence according to which "political liberties could be protected from authoritarian governments only by the widespread ownership of individual private property" (ibid.), Chinese Zhongguancun had not a similar ideological background to establish its idea of creativity.

During this second stage, entrepreneurs and policy makers started to debate on the identity of Zhongguancun and its eventual role within the international market. In 2003, an article on Computer World suggested three solutions that were: first, to improve Haidian district skills in bridging the needs of government and enterprises; second, to improve the entrepreneurs approach encouraging them to invest more on ambitious projects; third to follow the standards of the Silicon Valley investing more on talent cultivation. The success of this last point is crucial because it requires time and long- term plan to open different channels to provide knowledge from foreign experience (Computer World, 2003). The issue to shape the profile of Zhongguancun on the basis of the Silicon Valley's experience led to an articulated debate. Indeed, another article on Computer World on October 2003 questioned whether the present development of 
Zhongguancun was compatible with the Silicon Valley model. According to the editorial, the local and nationalal government had not a clear vision on the mid-long-term strategy for the Haidian district, thus it was necessary to focus on GDP development or innovation. During this second stage, the majority of Chinese companies were not focused on research and technology development as these two factors were perceived as threats for future economic sustainability of the abovementioned companies (Computer World, 2003). If, during the first period, the profit margins of the activities mainly based on trade was higher than 100\%, during the second period mainstream enterprises moved to a process of industrialization: during the last part of this second period many companies realized that the main goal was to invest on innovation by developing core technology (Computer World 2003). The last main difference between Zhongguancun and Silicon Valley laid on the number of SME, viewed as a "source of vitality for creativity" (Ibid.). During this second stage Zhongguancun polices were criticized to be too focused on big companies, a trend that was also confirmed by a survey published on Computer World according to which in 2003, about $80 \%$ of SMSs in Zhongguancun moved out from Haidian district because of the high operating costs (ibid). Despite the existing academic literature and editorials that emphasize the role of the USA policies for the development of Zhongguancun, as it is visible in the case of the already mentioned article "Silicon Valley is not accidental" in 2004, during this second stage Zhongguancun was still in search of developing a clear imaginary fully based on neoliberal values and therefore its model was still far away from the Californian one. One clear example for this is provided by the PC manufacturing company Lenovo that, in 2005, with its $30 \%$ market share, was the only Chinese brand (along with Founder) (Computer World, 2006) to represent a credible alternative to the other three foreign brands (Hewlett - Packard, Dell and Acer). The main issue was that excluding Lenovo, Founder and other university backed enterprises, PC enterprises in China had "unclear property rights" (Computer World, 2003): this situation obstructed the creation of a competitive environment, it supported a mainly top down and government driven market, and it postponed the creation of a creative business environment.

\section{From 2009 to 2019 towards a Service Area}

During the third and last stage of Zhongguancun, businessman and policymakers realized that, following the development of the second phase was not sustainable for the Haidian district, thus a more original and domestic model was to be considered. In general, as it has been also confirmed by our quantitative analysis, we assisted to a shift from a narrative based on the idea of creativity to a new one based on the idea of innovation. The major confirmation in this sense is provided by the Reply of the State Council on agreeing to support the construction of the National Independent Innovation Demonstration Zone in Zhongguancun Science Park published on March 2009 in which it was clearly stated that the goal was to "build a national independent innovation demonstration zone in Zhongguancun Scence Park, benefiting from the advantages of innovative resources [...] and cultivating the most innovative talents" (art. 1). The main goal was to "improve the independent innovation capacity of Zhogguancun Science Park, promoting its technological development and innovation to a new level in the next 20 years so as Zhongguancun Science and Technology Park could become a global centre for technology innovation" (ibid).

Another example in this sense is provided by the phenomenon of Garage coffees that begun to be developed in the West district of Zhongguancun. An editorial published on the magazine Zhongguancun in May 2012 specified that the role of garage coffees was "not only to provide an office space for early entrepreneurs, but also to provide a platform of communication between entrepreneurial projects and investors with the final goal to become a grassroot entrepreneurial platform" (Computer World, 2012). The shift from creativity to innovation was also boosted by the Internet and mobile internet. Supporting a deterministic vision, the idea is that the "new technology of mobile internet caused traditional industries to face challenges and opportunities in their services and management systems (Computer World, 2014). It is possible to argue that this change was also facilitated by national funds and ad hoc policies also this time paying a particular attention to attract overseas entrepreneurs and/or Chinese entrepreneurs back to Zhongguancun in order to create incubators, to support the exchange of technology and to attrac more loans. Nevertheless, Silicon Valley kept on playing a consistent impact on the Chinese policymakers' imaginary. Not surprisingly, a quite successful funding program between private sector and Beijing municipality program was called "micro Silicon Valley". The California area was still viewed as an example to be followed and replicated especially from the economic performances and structure. One key issue in this respect was and still is the 
role played by angel investors. An article published on Computer World on April 2013 noted that a report published by Forbes in January 2012 highlighted that all the ten biggest entrepreneurship incubators in the United States had angel investors to support their projects. However, according to the statistics provided by Zhonggauncun Management Committee, at the end of June 2012 there were only 300 angel investors on a base of 6000 incubators and among them only 55 had a major business (Computer World, 2013).

Furthermore, the Silicon Valley was still representing a model also to create innovation with business purposes. Although we argued that universities like Peking and Tsinghua played an important role to push researchers towards the technology market, especially during the first stage of the Haidian district, during its third stage Zhonggauncun had still not a single university that could establish an effective connection between research and business needs. In other words, compared to the Silicon Valley, Haidian district had not its Stanford. This is the reason why on April 2015 the Haidian district municipality decided to create a "college students' entrepreneur street" to implement a project called "People's entrepreneurship and innovation" (Zhonggauncun, 2013). The project was a starting point to support "public entrepreneurship and innovation" (ibid.).

Lastly, yet important, the narrative of our sources emphasizes a kind of superiority of the Silicon Valley even in providing successful stories in the history of Zhongguancun. This is particularly true in the cover story of Wang Dongling published on Computer World on November 2016. Wang's experience in Haidian district is particularly significant because in 1995 he developed a local electronic document technology which successfully challenged big companies such as Adobe and Microsoft, especially thanks to the support of big Chinese Bank as the Agriculture Bank of China and eventually other academic institutions and enterprises that enabled Wang product to cover more than $90 \%$ of the electronic document market as well as to be implemented also by the General Office of the State of Council as government software used to share electronic documents. Despite his massive success in China, in 2010, at the age of 40, Wang decided to start his own project in the Silicon Valley, a place where, according to the same words of Wang, "everyone is respectful of technology and technology can be successful in the market" (Computer World, 2016). Even more emblematic are the doubts of the same Chinese engineer who lamented how in the past "a lot of people in China, included my investors, told me that there was never a domestic company driven by an interest in technology and successful into the market" (ibid). According to Wang, the reason why China failed in carrying out the Silicon Valley model was Chinese obsession for the market ("in China you should just be a businessman").

\section{CONCLUSIONS, DIFFERENT ENVIRONMENTS, SAME NARRATIVE: A CHINESE PARADOX}

The analysis of our sources shows that during its three stages, Zhongguancun experienced an industrial progress mainly driven by top down national and local policies that created the conditions not only to establish a creative area first and an innovation park later, but also to lunch hardware and software successful companies in the domestic market. Our findings also demonstrate that during the three phases Zhongguancun has been significantly influenced by the successful experience of the Silicon Valley, highlighting key topics such as the role of angel investors, business mentality and the capacity of universities to transfer technology to the market. The paradox is that, especially during the first stage, both Computer World and Zhongguancun focused their reports and editorials in showing how the Silicon Valley was also the result of top down and US government supported policies and activities.

If, on the one hand, it is possible to argue that Zhongguancun fairly reflects the shift of Chinese society towards a "new China", with a specific refence to the change from the "made in China" (during the first and second stages) to the desire to "create in China" (during the third stage); on the other hand, most of the narrative and the imaginary supported by two of the most important hi tech magazines address a constant criticism to the Chinese model, suggesting to get benefit and inspiration from the Californian one.

Our selected articles also provide three main contradictions in the narrative of Zhogguancun. Experiences in the 1990s like the one of the software provided by Wang Dongling in the field of electronic document as well as the production of original digital printing system, Chinese PC typesetting and Chinese language 
computer card that could search Chinese words automatically reflects a wave of creativity during the first stage that is not present in the second and third stages. Second, during the second stage Zhongguancun started to face similar problems already present in the Silicon Valley. For instance, the real estate issue is not only a common problem in California and in Beijing Haidian district; even worst, according to our Chinese sources, it is considered a bubble that can compromise the economic and creative development of Zhongguancun itself. Third, the launch of innovation places, like innovation cafes, and the expected higher engagement of angel investors and incubators demonstrate that, during its third stage, Zhongguancun is consolidating a model based on neoliberal values not totally in line with its constitutive choices made at the end of the 80s.

Our article ends with the challenge to context or at least to reevaluate the narrative and the imaginary of Zhogguancun as a mere "Chinese Silicon Valley". The development of Beijing Haidian area has been aimed at presenting itself as an alternative to the Californian region; however, historical, political, cultural and economic issues not only delayed the success of this plan but also created the conditions of a mutual reciprocity between the two districts. Indeed, our findings suggests that Zhongguancun does still need to improve its know-how, its mentality and its financial plans to achieve its goal. The continuous reference to the Silicon Valley successfully stories, the choice of Chinese entrepreneurs to launch their start up in the U.S. as well as the return of young Chinese researchers trained outside China, highlight a still clear dependency to California and Silicon Valley not only at the ideal but also at the practical level.

Finally, the results of our article provide a more nuanced perspective on the overestimated Chinese digital "revolution" showing that experiences like Zhongguancun are not linear and should be considered as the result of a negotiation between different agents as well as domestic and international influences (in our case the role of Silicon Valley) that have its roots in the 80s already, even before of the development of the Internet in China. We hope more empirical and qualitative studies can positively influence futures projects and policies of one of the most important creative districts in the world, still in search of a clear identity.

\section{ACKNOWLEDGEMENTS}

Part of the data collection of the present paper was supported by the Sino Swiss Science and Cooperation Program. The authors express their gratitude to Mrs. Liu Chenchen from the Embassy of Switzerland in China and the Mr. Su Di curator of the Zhongguancun Entrepreneurship Museum.

\section{REFERENCES}

Anderson, C. (2007) The Long Tail. How Endless Choice Is Creating Unlimited Demand. London: Random House Business. https://doi.org/10.1007/s10824-007-9038-7

Arsène, S. (2012, May). The impact of China on global Internet governance in an era of privatized control. In Chinese Internet Research Conference.

Aydalot, P., \& Keeble, D. (2018). High technology industry and innovative environments: the European experience. Routledge. https://doi.org/10.4324/9781315149769

Balbi, G., \& Magaudda, P. (2018). A History of Digital Media. An Intermedia and Global Perspective. New York. https://doi.org/10.4324/9781315209630

Barbrook, R. (2007). Imaginary futures: From thinking machines to the global village. Pluto Press.

Barbrook, R., \& Cameron, A. (1996). The californian ideology. Science as Culture, 6(1), 44-72. https://doi.org/10.1080/09505439609526455

Benner, C. (2003). Learning communities in a learning region: the soft infrastructure of cross-firm learning networks in Silicon Valley. Env. and planning A, 35(10), 1809-1830. https://doi.org/10.1068/a35238

Björner, E. (2014). Imagineering Chinese mega-cities in the age of globalization. Branding Chinese Mega-Cities: Policies, Practices and Positioning; Berg, PO, Björner, E., Eds, 106-120. https://doi.org/10.4337/9781783470334.00015

Borrup, T. (2011). The emergence of a new cultural infrastructure: Lessons from Silicon Valley. Journal of Urban Culture Research, 2, 16-29. https://doi.org/10.14456/jucr.2011.1 
Cao, C. (2004). Zhongguancun and China's High-Tech Parks in Transition: "Growing Pains" or "Premature Senility"?. Asian Survey, 44(5), 647-668. https://doi.org/10.1525/as.2004.44.5.647

Casper, S. (2007). Creating Silicon Valley in Europe: Public policy towards new technology industries. Oxford University Press. https://doi.org/10.1093/acprof:oso/9780199269525.001.0001

Castells, M. (2014). Technopoles of the world: The making of 21st century industrial complexes. Routledge. https://doi.org/10.4324/9781315832203

CB Insights. (2020). What is a Unicorn Startup? Retrieved on 25 March 2020 from https://www.cbinsights.com/research-unicorn-companies

Chow, R., Harootunian, H., \& Miyoshi, M. (1996). Global/local: Cultural production and the transnational imaginary. Duke University Press.

Cook, I., \& Joseph, R. (2001). Rethinking Silicon Valley: new perspectives on regional development. Prometheus, 19(4), 377-393. https://doi.org/10.1080/08109020110091431

Ding, X., \& Li, J. (2015). Incentives for innovation in China: Building an innovative economy. Routledge. https://doi.org/10.4324/9781315726717

Duff, A. S. (2016). Rating the revolution: Silicon Valley in normative perspective. Information, Communication \& Society, 19(11), 1605-1621. https://doi.org/10.1080/1369118X.2016.1142594

Dyson, E. (1996). Cyberspace and the American Dream: A Magna Carta for the Knowledge Age (Release 1.2, August 22, 1994). The information society, 12(3), 295-308. https://doi.org/10.1080/019722496129486

Etzkowitz, H. (2011). Silicon Valley: The sustainability of an innovative region. In Commercialising University Research Workshop, University of London Birkbeck, Centre for Innovation.

Etzkowitz, H. (2019). Is Silicon Valley a global model or unique anomaly?. Industry and Higher Edu., 33(2), 83-95. https://doi.org/10.1177/0950422218817734

Etzkowitz, H., \& Zhou, C. (2017). The triple helix: University-industry-government innovation and entrepreneurship. Routledge. https://doi.org/10.4324/9781315620183

Even, M. P., \& Street, J. (2018). The Silicon Valley Novel. Literature \& History, 27(1), 81-97. https://doi.org/10.1177/0306197318755680

Francis, C. B. (1996). Reproduction of danwei institutional features in the context of China's market economy: The case of Haidian district's high-tech sector. The China Quarterly, 147, 839-859. https://doi.org/10.1017/S0305741000051821

Fuchs, C. (2014). Theorising and analysing digital labour: From global value chains to modes of production. The Political Economy of Communication, 1(2).

Fung, K. C., Aminian, N., \& Tung, C. Y. (2016). Some characteristics of innovation activities: Silicon Valley, California, China and Taiwan. Economic Change and Restructuring, 49(2-3), 221-240. https://doi.org/10.1007/s10644-015-9162-x

Fursich, E. (2009). In defense of textual analysis. Journalism studies, 10(2), 238-252. https://doi.org/10.1080/14616700802374050

Gittings, J. (2005) The Changing Face of China. From Mao to Market. Oxford: Oxford University Press.

Haour, G., \& von Zedtwitz, M. (2016). Created in China: How China is becoming a global innovator. Bloomsbury Publishing.

Hartley, J., \& Montgomery, L. (2009). Creative industries come to China (MATE). Chinese journal of Communication, 2(1), 1-12. https://doi.org/10.1080/17544750802638798

Henton, D., \& Held, K. (2013). The dynamics of Silicon Valley: Creative destruction and the evolution of the innovation habitat. Social science info., 52(4), 539-557. https://doi.org/10.1177/0539018413497542

Hong, Y. (2017). Networking China: The Digital Transformation of the Chinese Economy. Urbana, University of Illinois Press.

Hynes, C. (2017). Beijing - Non Silicon Valley is the World's Top Tech Hub, Report Say. Forbes, 2 November. Retrieved from https://www.forbes.com/sites/chynes/2017/11/02/has-beijing-unseated-silicon-valleyas-the-worlds-top-tech-hub-one-report-says-yes/\#363feb4d7acf

Indergaard, M. (2004). Silicon Alley: the rise and fall of a new media district. Routledge. https://doi.org/10.4324/9780203496596

Keane, M. (2007). Created in China: The great new leap forward. Routledge. https://doi.org/10.4324/9780203937471 
Keane, M. (2009). Creative industries in China: four perspectives on social transformation. International Journal of Cultural Policy, 15(4), 431-443. https://doi.org/10.1080/10286630902989019

Klingler-Vidra, R. (2016). Diffusion and adaptation: why even the Silicon Valley model is adapted as it diffuses to East Asia. The Pacific Review, 29(5), 761-784. https://doi.org/10.1080/09512748.2015.1022592

Lindtner, S., \& Li, D. (2012). Created in China: the makings of China's hackerspace community. interactions, 19(6), 18-22. https://doi.org/10.1145/2377783.2377789

Ling. Z. (2006). The Lenovo affair: the growth of China's computer giant and its takeover of IBM-PC. Singapore, John Wiley \& Sons.

Marwick, A. (2013). Silicon Valley Isn't a Meritocracy. And It's Dangerous to Hero-Worship Entrepreneurs. WIRED, November. Retrieved from http://www.wired.com/2013/11/silicon-valley-isnt-a-meritocracy-andthe-cult-of-the-entrepreneur-holds-people-back

Mazzucato, M. (2011). The entrepreneurial state. Soundings, 49(49), 131-142. https://doi.org/10.3898/136266211798411183

Meng, B. (2018). The politics of Chinese media consensus and contestation. New York: Palgrave Macmillian. https://doi.org/10.1057/978-1-137-46214-5

Molnar, M., \& Koen, V. (2015). Providing the right skills to all in China. https://doi.org/10.1787/18151973

Peet, R. (2000). Culture, imaginary, and rationality in regional economic development. Environment and Planning A, 32(7), 1215-1234. https://doi.org/10.1068/a3250

Repnikova, M. (2017). Media politics in China: Improvising power under authoritarianism. Cambridge University Press. https://doi.org/10.1017/9781108164474

Rosen, S. (2004). The victory of materialism: aspirations to join China's urban moneyed classes and the commercialization of education. The China Journal, (51), 27-51. https://doi.org/10.2307/3182145

Schiller, D. (2011). Power under pressure: Digital capitalism in crisis. Inter. Journal of Communication, 5, 18.

Starr, P. (2004). The creation of the media: Political origins of modern communications (p. 153). New York: Basic Books.

Taylor, M. Z. (2004). Empirical evidence against varieties of capitalism's theory of technological innovation. International Organization, 58(3), 601-631. https://doi.org/10.1017/S0020818304583066

Trunina, A., Liu, X., \& Chen, J. (2019). Small and medium technology enterprises in Zhongguancun and Silicon Valley: Regional innovation system approach. Journal of Science and Technology Policy Management, 10(1), 35-57. https://doi.org/10.1108/JSTPM-01-2018-0006

Turner, F. (2010). From counterculture to cyberculture: Stewart Brand, the Whole Earth Network, and the rise of digital utopianism. Chicago. University of Chicago Press.

Wajcman, J. (2018). How Silicon Valley sets time. New Media \& Society, 1461444818820073. https://doi.org/10.1177/1461444818820073

Warner, M. (1999). Human resources and management in China's' hi-tech'revolution: A study of selected computer hardware, software and related firms in the PRC. International Journal of Human Resource Management, 10(1), 1-20. https://doi.org/10.1080/095851999340602

Wolf, M. J. (2014). Building imaginary worlds: The theory and history of subcreation. Routledge. https://doi.org/10.4324/9780203096994

Wu, J., \& Yun, G. (2018). From modernization to neoliberalism? How IT opinion leaders imagine the information society. International Communication Gazette, 80(1), 7-29. https://doi.org/10.1177/1748048517742773

Yang, G. (2009). The power of the Internet in China: Citizen activism online. Columbia University Press.

$\mathrm{Yu}, \mathrm{H}$ (2017) Networking China. The Digital Transformation of the Chinese Economy, Urbana, University of Illinois Press.

Yu, H. (2011). Doing Chinese media studies: A reflection on the field's history and methodology. Media International Australia, 138(1), 66-79. https://doi.org/10.1177/1329878X1113800109

Zhao, Y. (2009). «Rethinking Chinese media studies: history, political economy, and culture》 Daya Thussu (Eds) Internationalizing media studies (pp. 175-195). London: Routledge.

Zhou, Y. (2005). The making of an innovative region from a centrally planned economy: institutional evolution in Zhongguancun Science Park in Beijing. Environment and Planning A, 37(6), 1113-1134. https://doi.org/10.1068/a3716

Zhou, Y. (2006). Historicizing online politics: Telegraphy, the Internet, and political participation in China. Stanford University Press. 
Zhou, Y. (2007). The inside story of China's high-tech industry: Making Silicon Valley in Beijing. Rowman \& Littlefield Publishers.

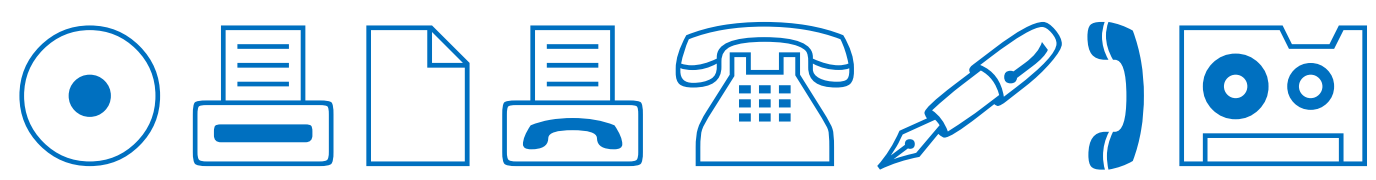

